\title{
Extracurricular Education to Increase Nutrition Knowledge Among Primary School Children in Indonesia
}

\author{
Mauliddya Rahmadina ${ }^{*}$, Sandra Fikawati ${ }^{2}$, Ahmad Syafiq ${ }^{3}$ \\ \{mauliddya.rahmadina71@ui.ac.id ${ }^{1}$, fikawati@ui.ac.id², asq69@yahoo.co.uk\} \\ Faculty of Public Health, University of Indonesia, Indonesia ${ }^{1-3}$
}

\begin{abstract}
Increased nutritional knowledge has been shown to increase one's awareness in implementing healthy living behaviors. The school approach of nutrition education through intracurricular curriculum and extracurricular activities will improve the nutrition knowledge of elementary school children. This study aims to compare the knowledge of elementary school students without and with the intervention of the Gerakan Nusantara as extracurricular activities in schools. This research is a descriptive qualitative analysis and statistical analysis. The results showed that Gerakan Nusantara, as an extracurricular activity, was proven to be able to improve the nutrition knowledge of elementary school children. This program supports the existing subject matter in the students' intracurricular curriculum in elementary schools. Increased knowledge with the intervention of the Gerakan Nusantara Program because the program serves the materials along with interesting animated images, healthy feeding practices, outdoor physical activity, and involving all parties related to students, namely the school teacher, peers, and parents.
\end{abstract}

Keywords: extracurricular, education, nutrition, elementary school, gerakan nusantara

\section{Introduction}

According to the Center for Data and Information of the Indonesian Ministry of Health in 2016, the nutritional condition of school-age children still needs attention, reflected in the percentage of stunting, which reached $30.7 \%$, meaning that Indonesian children still have poor nutritional status [1]. Indonesia is currently one of the countries with a high prevalence of stunting compared to other low-income countries [2]. Therefore, nutrition education interventions are needed so that children can adopt healthy living behaviors and apply a balanced nutritional intake.

Good nutritional intake will have a positive impact on child growth and intelligence. Children who have poor nutrition are a lack of vitamins and minerals (vitamin A, iron, iodine). They will grow slower and have less energy to play, physical activity, poor attention, and problems in school [3]. School-age children (6 to 12 years old) require large amounts of energy to play, school activities, physical activities, storing optimal nutrient reserves for rapid body 
growth/growth spurt in adolescence and maturation of reproductive organs, so that a lot of energy reserves are needed.

Health status in school-age children greatly influences the quality of education [4]. To create a golden generation (qualified human resources), character, and health, the understanding of nutrition should be introduced from an early age at the basic education level (SD/MI). It is intended that students have insight about nutrition. This insight can be a provision for students in choosing good food intake for their bodies so that their health is maintained [5].

Various interventions have been carried out to deal with nutrition problems in school-age children. One of the interventions is nutrition education, which aims to increase nutrition knowledge in school-age children. Through this intervention, school-age children are expected to be able to apply healthy lifestyles and balanced nutritional intake in their daily lives, so that their nutritional status improves, along with improving the quality of children's education and achievement.

Nutrition education in schools is very important to facilitate health education and improve healthy lifestyle habits [6]. Nutrition education in schools has several advantages: children have an open mind compared to adults, and the knowledge received will be the basis for fostering children's eating habits. Nutrition education in schools aims to enable children to influence their family's habits to follow good nutrition. Besides, it also helps children have the knowledge, attitudes, and good practices about food consumption [7]. The school approach to a healthy diet improves the knowledge and skills of children and adolescents. It is be implemented inside and outside of school. Besides, nutrition education at school makes schools a health promotion and nutrition promotion to improve achievement, strengthen the capacity of schools to deal with health problems and child, family, and community nutrition. It also strengthens networks between schools, students, parents, the community, local health, and education authorities. It can prevent health problems related to nutrition in developing countries. Moreover, the program will enable schools to become "Nutrition Friendly" as a means of good nutrition education interventions [8].

Nutrition education in school curricula across the world is still low, the time dedicated is small, and progress is slow, partly resulting from lengthy curriculum revision processes, pressure on school timetables, and conceptual innovations [9]. In Indonesia, nutrition education in the school intracuricular curriculum is still relatively small. Nutrition education in the curriculum is not studied at all grade levels and contains limited nutrition material. Nutrition education needs to be considered as an effort to improve the nutrition knowledge of students [10]. Nutrition education in schools seems not optimum since the teachers have no competencies about the issue. However, it is not easy to modify the curriculum because it is developed centrally and contains various disciplines should be included in the curriculum [11]. Therefore, an alternative learning method is needed to support nutrition education in the intracuricular, namely extracurricular activities.

Extracurricular activities are a series of activities outside the intracuricular that can provide additional knowledge and benefits for students. Extracurricular education, according to Permendikbud number 62 of 2014 article 1 paragraph 1, is a curricular activity carried out by students outside of the learning hours of intracuricular activities and co-curricular activities under the guidance and supervision of the education unit [12]. Extracurricular activities are pathways to enhance student knowledge, which in accordance with the existing curriculum. It can also complement coaching efforts, establish and shape the personality values of students, fostering and increasing talent, the interests and skills and expected outcomes are to spur children to be independent, confident, and creative [13]. 
Gerakan Nusantara (Gernus) Program is an extracurricular activity at school providing teacher training activities, nutrition education for students, outdoor physical activities, milk distribution for students, and seminars for parents. Gernus strive to improve the achievement of national education goals through activities aimed at implementing healthy living behaviors, eating nutritionally balanced foods, exercising, and getting used to drinking milk every day. Program Gernus conceived by PT. Frisian Flag Indonesia (FFI), started in 2013 and reached more than 600,000 elementary students in several cities in Indonesia. FFI works with Pusat Kajian Gizi dan Kesehatan Universitas Indonesia (PKGK UI) also measured the impact of children's healthy and active behavior through KAP (Knowledge-Attitude-Practice) studies from 2014 to 2018 [14]. This study aims to compare the nutritional knowledge of elementary school students without and with nutrition education interventions through the extracurricular activities of the Gernus Program.

\section{Method}

Descriptive analysis research was carried out on nutrition content in the elementary school curriculum and nutrition education material provided by the Gernus Program. The curriculum nutrition education content was analyzed using primary data obtained from Curriculum of 2013 elementary school textbooks and the syllabus Curriculum of 2013 for elementary school teachers designed by the Ministry of Education and Culture (Kemendikbud). Analysis of nutrient content on Gernus material also uses primary data by evaluating the Gernus nutrition education flipchart and the Gernus nutrition education book.

The analysis was carried out qualitatively by identifying the type of presentation and the type of description of the material. Nutrition education content is measured by the type of description and presentation of material in textbooks, teacher syllabus, flipcharts, and student nutrition education books. According to Syarief et al. in Adhistiana, description types of the subject can be divided into three types, namely glance types, short types, and complete types. Glance Type is the form of words, phrases, short sentences, single images, or a collection of non-story images. Short types are complete sentences, short paragraphs, complete tables, series of story descriptions, or points without explanation. The complete type is in the form of a complete paragraph or points with an explanation. The types of presentation of subjects divided into two types, namely sentence type, and picture type. A subject is the type of sentence if it is in the form of sentences or tables, and the type of pictures if it is in the form of pictures [10].

The type of presentation and the type of description are each given a rating of 1 (one) to 3 (three) points. Type of description is given 1 (one) point for the type of description at a glance, 2 (two) points for the type of short description, 3 (three) points for the type of complete description, while for the type of presentation given 1 (one) point for the type of image presentation, 2 (two) points for the type of sentence presentation, and 3 (three) points for the type of image and sentence presentation. Assessment is done with the highest total points score of 6 (six) points, and the lowest total score of points is 2 (two) points.

Changes in knowledge were obtained from statistical analysis using SPSS software so that nutritional knowledge of elementary school students can be compared without and with nutrition education interventions through Gernus extracurricular activities. The data used are secondary data from the Gernus Knowledge, Attitudes and Practices survey (KAP) from 2014 to 2018. The data used in the KAP study were only grade 5 students. The total sample of grade 5 
elementary school students taken was 3,585 people from elementary schools in Jakarta, Bandung, Surabaya, Makasar, Medan, Banten, Pontianak, Jambi, Padang, Pekan Baru and Propinsi Jawa Timur, Nusa Tenggara Timur, Papua Barat.

The results of data processing using SPSS are presented with a table that presents the mean values before and after the standardized intervention with the lowest value of 0 and the highest value of 100 . The score is set by dividing the average score before and or after multiplied by 100. The dependent t-test was performed to see changes in knowledge scores between without and with nutrition education interventions. The results of the analysis declared significant if the significance value $(\mathrm{p}<0,05)$.

\section{Result}

\subsection{Nutrient Content in the Intrakuricular}

The curriculum used in schools from 2014 to 2018 is the Curriculum 2013 (K13), arranged thematically, or integrated. Integrated thematic learning is a learning approach that integrates various competencies from various subjects into various themes. Determination of the theme used as a big idea of learning that connects the concepts and competencies to be achieved by students [15].

Nutritional content within Intrakurikuler is identified from the syllabus of the Curriculum 2013 teacher's handbook and the Curriculum 2013 elementary school textbooks based on the type of description and type of presentation. The identification of nutritional content in textbooks is presented in Table 1. Nutrition content in textbooks is divided by type of description, type of presentation, type point score, and total score.

The type of material description is a glance type in the form of words, phrases, short sentences, single images, or a collection of non-story images. Short types are complete sentences, short paragraphs, complete tables, series of story descriptions, or points without explanation. Complete type is a complete paragraph or bullet with an explanation. Evaluation of description types is scored 1 (one) point for a glance description type, 2 (two) points for a short description type, 3 (three) points for complete description type. Scoring for the type of presentation is given 1 (one) point for the type of presentation of images, 2 (two) points for the type of presentation of sentences, and 3 (three) points for the type of presentation of images and sentences. The highest total points score is 6 (six) points, and the lowest total points score is 2 (two) points [10]. 
Table 1. Nutrition Content in Curriculum 2013 Based on Description Type, Presentation Type, Score Point of Type and Total Score

\begin{tabular}{|c|c|c|c|c|c|c|}
\hline \multirow[t]{2}{*}{ Grade } & \multirow[t]{2}{*}{ Sub Tema } & \multirow{2}{*}{$\begin{array}{l}\text { Description } \\
\text { Type }\end{array}$} & \multirow[t]{2}{*}{ Presentation Type } & \multicolumn{2}{|c|}{ Score Point of Type } & \multirow{2}{*}{$\begin{array}{r}\text { Total } \\
\text { Score }\end{array}$} \\
\hline & & & & Description & Presentation & \\
\hline \multirow[t]{6}{*}{$\mathrm{I}$} & Find the information on how to care for the body & Glance & Picture \& Sentence & 1 & 3 & 4 \\
\hline & Practices for caring for the body (brushing teeth, washing hands, bathing, shampooing) & Glance & Picture & 1 & 1 & 2 \\
\hline & How to maintain cleanliness of the body and clothes & Short & Picture \& Sentence & 2 & 3 & 5 \\
\hline & Arrange how to care for the body based on body care pictures & Glance & Picture & 1 & 1 & 2 \\
\hline & Read stories about the benefits of exercise & Glance & Picture \& Sentence & 1 & 3 & 4 \\
\hline & The act of keeping the environment clean at home & Glance & Picture \& Sentence & 1 & 3 & 4 \\
\hline \multirow[t]{8}{*}{ III } & Read texts about food for health & Complete & Sentence & 3 & 2 & 5 \\
\hline & The importance of eating healthy and the reasons for choosing good food consumed & Glance & Sentence & 1 & 2 & 3 \\
\hline & Find advice sentences in texts related to body health & Short & Picture \& Sentence & 2 & 3 & 5 \\
\hline & Advice related to body health and explain its purpose & Short & Picture \& Sentence & 2 & 3 & 5 \\
\hline & Healthy food advice & Short & Sentence & 2 & 2 & 4 \\
\hline & Discuss how to choose healthy foods & Glance & Sentence & 1 & 2 & 3 \\
\hline & Identifying healthy food & Glance & Sentence & 1 & 2 & 3 \\
\hline & Interviews about healthy snacks & Glance & Picture \& Sentence & 1 & 3 & 4 \\
\hline \multirow[t]{8}{*}{ IV } & Text about healthy and nutritious food & Short & Picture \& Sentence & 2 & 3 & 5 \\
\hline & Looking for healthy and nutritious food information & Glance & Sentence & 1 & 2 & 3 \\
\hline & Discuss healthy and nutritious food & Glance & Sentence & 1 & 2 & 3 \\
\hline & Read the table of nutritional needs according to body weight, height, age & Short & Sentence & 2 & 2 & 4 \\
\hline & Identify children who are malnourished, obese, and normal & Glance & Picture & 1 & 1 & 2 \\
\hline & The benefits of healthy and nutritious food for growth & Complete & Sentence & 3 & 2 & 5 \\
\hline & Information on the benefits of healthy and nutritious foods typical of the region & Short & Sentence & 2 & 2 & 4 \\
\hline & The habit of eating healthy and nutritious food in the morning & Complete & Sentence & 3 & 2 & 5 \\
\hline \multirow[t]{5}{*}{$\mathrm{V}$} & Identify food consumed daily in the environment & Complete & Sentence & 3 & 2 & 5 \\
\hline & Watch advertising pictures about healthy food & Short & Picture & 2 & 1 & 3 \\
\hline & Observing advertisements the importance of water & Glance & Picture & 1 & 1 & 2 \\
\hline & Look at the text reading about healthy food & Complete & Sentence & 3 & 2 & 5 \\
\hline & Impact of unhealthy foods on the digestive organs & Complete & Sentence & 3 & 2 & 5 \\
\hline
\end{tabular}


The results of the analysis of nutritional content in 2013 Curriculum textbooks in Table 1 obtained the highest total score of 5 (five) for sub themes; How to maintain the cleanliness of the body and clothes; read texts about food for health; Find advice sentences in texts related to body health; Find advice sentences in texts related to body health Text about healthy and nutritious food; The benefits of healthy and nutritious food for growth; The habit of eating healthy and nutritious food in the morning; Identify food consumed daily in the environment; Look at the text reading about healthy food; and Impact of unhealthy foods on the digestive organs.

The total score of 4 (four) for sub-themes Find the information on how to care for the body, Read stories about the benefits of exercise, The act of keeping the environment clean at home, Healthy food advice, Interviews about healthy snacks, Read the table of nutritional needs according to body weight, height, age, Information on the benefits of healthy and nutritious foods typical of the region

Total score 3 for sub-theme "The importance of eating healthy and the reasons for choosing good food consumed", "Discuss how to choose healthy foods", "Identifying healthy food, Looking for healthy and nutritious food information", "Discuss healthy and nutritious food", and "Watch advertising pictures about healthy food

"

The lowest score is 2 for sub-theme "Practices for caring for the body (brushing teeth, washing hands, bathing, shampooing)", "Arrange how to care for the body based on body care pictures", "Identify children who are malnourished, obese, and normal", and "Observing advertisements the importance of water".

\subsection{Nutrition Content in the Gerakan Nusantara}

PT Frisian Flag Indonesia initiated Gerakan Nusantara (Gernus) (FFI), motivated by the results of the SEANUTS study, which shows that Indonesian children experience a double burden issue, namely malnutrition \& overweight. In addition, Indonesian children also experience Vitamin D deficiency, with a low level of activity. The purpose of the Gernus is to increase the achievement of national education goals through activities which aim to implement healthy living behaviors, eat balanced nutritious food, exercise, and get used to drinking milk every day.

Gernus was initiated by FFI in collaboration with the Center for Nutrition and Health Studies, University of Indonesia (PKGK UI), and the Indonesian National Drug and Food Control Agency (BPOM RI). Gernus activities consist of; nutrition education activities for students in the classroom, outdoor activities, distribution of milk for students, distribution of nutrition education booklets, renovation and socialization of healthy canteens, training activities called Training of Trainers (ToT) on nutrition for Teachers, Student training, and Parent seminars. Gernus also measures the positive impact on the healthy and active behavior of children through KAP (Knowledge-Attitude-Practice) study conducted by PKGK UI.

Gernus activities were carried out in 5 cities in Indonesia (Jakarta, Bandung, Surabaya, Makassar, and Medan) in 2014 and 2015, in 6 cities (Banten, Bandung, Yogya, Jatim, Pontianak, NTT) in 2016, in 3 cities (Jambi, Padang, Pekanbaru) in 2017 dan three provinces (Jawa Timur, Nusa Tenggara Timur, dan Papua Barat) in 2018. Presenters, nutrition information materials, and training aids facilitated by PT. Frisian Flag Indonesia, in collaboration with PKGK UI. Material is given to teachers, students, and parents. Before the training material is conducted, KAP studies/surveys are first conducted to assess and evaluate the success of the program. The KAP study selected 40 students purposively from grades IV and V to do a pre-test and post-test to assess the success of the program. 
In the Teacher Training or Training of Trainers (TOT) activities, 2-3 teachers from each school are chosen, namely the headmaster, grade IV or V teachers, and the person in charge of UKS. Selected teachers are given deepening of the material and filling in the teacher's diary. The training was given by video training, PPT, and Nutrition Education Flipchart. After the training, there is an obligation for teachers who have participated in TOT to train or socialize the nutrition material obtained to other teachers. Provision of material to other teachers at school is made at least 3 (three) times for 2 (two) weeks after TOT.

Furthermore, nutrition education for students is given by teachers who have received training. Student nutrition education material contains an explanation of the Balanced Nutrition Guidelines (PGS), milk consumption, healthy breakfast, physical activity, and healthy snacks. Education for students is done 1 (one) time per week, for 3 (three) months. The teacher gave the provision of balanced nutrition material to students in grades IV and $\mathrm{V}$ with animated videos, flipcharts, and nutrition education books.

Besides, there is student training for selected students, training material by PKGK UI. Student training is given to 2 students chosen by the Principal, who are considered active, confident, able to convey material clearly to their peers. The selected students are small doctors and students who have good achievements. This student training aims to enable students who have been given the training to share and pass on the knowledge they have gained to their peers

After nutrition education is given to students, students will be invited to do activities outside the classroom or outdoor activity, which aims to educate children to always be active every day according to the Gernus 2018 tag-line, i.e., Drink-Move-Be Strong. Outdoor activity activities with sports teachers to class III, IV, and V by doing gymnastics, playing basketball, and others. Furthermore, the series of activities in milk sampling. PT Frisian Flag Indonesia will give all students milk as the organizer of Gernus.

The training also involved parents in the Parents Seminar. The Parents Seminar aims to make parents able to carry out the materials that have been delivered at home and can share it with people around them, such as other family members, neighbors, and the community. PKGK UI gave this parenting seminar by inviting parents' representatives. The parent seminar is delivered at various school events, for example, at parent meetings, distribution of report cards, etc. Parents' seminar material includes a deepening of the materials for Student Nutrition Education activities. Parents' seminars are given using media PowerPoint (PPT).

The nutritional content in the flipchart and Gernus nutrition education books given to student training will be described in Table 2. as follows :

Table 2. Nutrition Contents in Gerakan Nusantara Student Education Materials

\begin{tabular}{|c|c|c|c|c|c|}
\hline \multirow{2}{*}{$\begin{array}{l}\text { Student } \quad \text { Nutrition } \\
\text { Education Materials }\end{array}$} & \multirow{2}{*}{$\begin{array}{l}\text { Description } \\
\text { Type }\end{array}$} & \multirow{2}{*}{$\begin{array}{l}\text { Presentation } \\
\text { Type }\end{array}$} & \multicolumn{2}{|c|}{ Score Point of Type } & \multirow{2}{*}{$\begin{array}{l}\text { Total } \\
\text { Score }\end{array}$} \\
\hline & & & Description & Presentation & \\
\hline $\begin{array}{l}\text { Types of nutrients and their } \\
\text { functions }\end{array}$ & Complete & $\begin{array}{l}\text { Picture \& } \\
\text { Sentence }\end{array}$ & 3 & 3 & 6 \\
\hline $\begin{array}{l}\text { Guidelines for balanced } \\
\text { nutrition (PGS) }\end{array}$ & Short & $\begin{array}{l}\text { Picture \& } \\
\text { Sentence }\end{array}$ & 2 & 3 & 5 \\
\hline $\begin{array}{l}\text { PGS - Tumpeng and Your } \\
\text { Dishes }\end{array}$ & Short & $\begin{array}{l}\text { Picture \& } \\
\text { Sentence }\end{array}$ & 2 & 3 & 5 \\
\hline PGS - Staple food group & Short & $\begin{array}{l}\text { Picture \& } \\
\text { Sentence }\end{array}$ & 2 & 3 & 5 \\
\hline $\begin{array}{l}\text { PGS - Fruit \& Vegetables } \\
\text { Group }\end{array}$ & Short & $\begin{array}{l}\text { Picture \& } \\
\text { Sentence }\end{array}$ & 2 & 3 & 5 \\
\hline
\end{tabular}




\begin{tabular}{|c|c|c|c|c|c|}
\hline $\begin{array}{l}\text { PGS - Fruit \& Vegetables } \\
\text { Colours Group }\end{array}$ & Short & $\begin{array}{l}\text { Picture \& } \\
\text { Sentence }\end{array}$ & 2 & 3 & 5 \\
\hline PGS - Complementary food) & Complete & $\begin{array}{l}\text { Picture \& } \\
\text { Sentence }\end{array}$ & 3 & 3 & 6 \\
\hline PGS - Water Consumption & Complete & $\begin{array}{l}\text { Picture \& } \\
\text { Sentence }\end{array}$ & 3 & 3 & 6 \\
\hline Consumption of milk & Complete & Sentence & 3 & 2 & 5 \\
\hline $\begin{array}{l}\text { Healthy Clean Living } \\
\text { Behavior (PHBS) }\end{array}$ & Short & $\begin{array}{l}\text { Picture \& } \\
\text { Sentence }\end{array}$ & 2 & 3 & 5 \\
\hline Outdoor Activity & Complete & $\begin{array}{l}\text { Picture \& } \\
\text { Sentence }\end{array}$ & 3 & 3 & 6 \\
\hline Healthy snacks & Complete & $\begin{array}{l}\text { Picture \& } \\
\text { Sentence }\end{array}$ & 3 & 3 & 6 \\
\hline Healthy Breakfast & Complete & $\begin{array}{l}\text { Picture \& } \\
\text { Sentence }\end{array}$ & 3 & 3 & 6 \\
\hline
\end{tabular}

Based on Table 2, it can be seen that the contents of nutrition education in the Gernus nutrition education flipchart and student nutrition education books are described shortly and completely and are presented with sentences and pictures and reach a maximum point score of 6 (six). The deepening of the material provided was in accordance with the recommendations of the Balanced Nutrition Guidelines (PGS) recommended by the Indonesian Ministry of Health. There are some additional discussions outlined in the nutrition education material for students that are not contained in the PGS, namely material on the fruit and vegetable color group, healthy breakfast, and healthy snacks.

Nutrition content in the flipchart and Gernus student nutrition education book is described shortly and completely in line with the nutrition content in the Curriculum 2013 textbooks. The nutritional content described in the material complements and adds to the material in the 2013 curriculum, most of which are briefly described. The addition of materials is about a color group of fruits and vegetables and the concept of healthy snacks and the benefits of consuming milk.

\subsection{Changes in Knowledge Before and After Intervention}

Changes in knowledge were analyzed based on variables before and after the Gernus intervention. Changes in knowledge are due to the provision of knowledge interventions through nutrition education. Table 3 shows changes in knowledge before and after the Gernus in 2014 nutrition education intervention. Based on the results of the t-test, it appears that in almost all materials, the value of the p-value is less than 0.05 , which means that it is statistically meaningful that there are significant differences in the level of knowledge before and after the intervention. Except for the PGS-Tumpeng and Piring Makanku (p-value 0.059), it means that there is no statistically significant difference in the level of knowledge before and after Gernus intervention.

The value of knowledge, it appears that the lowest value before and after the intervention is the PGS variable (20.0 and 32.5). The highest level of knowledge before and after the intervention is the Healthy Breakfast variable (86.0 and 91.0). The smallest change in value (d) of knowledge in 2014 was the Milk Consumption variable (-4.4), and the biggest change in value is the PGS-Water Intake variable (13.0). In the Milk Consumption variable (-4.4), there was a decrease in value after the intervention. But, the results of the t-test showed a p-value of 0.010 , which means that it is significant statistically significant there is a difference in knowledge between before and after Gernus intervention. 
Table 3. Change of Knowledge Before and After Gernus Nutrition Education Intervention in 2014

\begin{tabular}{|c|c|c|c|c|}
\hline \multirow{3}{*}{ Student Nutrition Education Materials } & \multicolumn{4}{|c|}{2014} \\
\hline & \multicolumn{3}{|c|}{ Score* } & \multirow{2}{*}{ p-value } \\
\hline & before & after & d & \\
\hline Types of Nutrients and Their Functions & 47.0 & 56.1 & 9.1 & 0.001 \\
\hline Guidelines for balanced nutrition (PGS) & 20.0 & 32.5 & 12.5 & 0.001 \\
\hline PGS - Tumpeng and Your Dishes & 39.2 & 41.5 & 2.3 & 0.059 \\
\hline PGS - Staple Food Group & 37.0 & 44.7 & 7.7 & 0.001 \\
\hline PGS - Fruit \& Vegetables Group & 48.0 & 51.7 & 3.7 & 0.030 \\
\hline PGS - Fruit \& Vegetables Colours Group & 65.0 & 77.0 & 12.0 & 0.001 \\
\hline PGS - Complementary food & 51.0 & 57.0 & 6.0 & 0.010 \\
\hline PGS - Water Consumption & 25.0 & 38.0 & 13.0 & 0.001 \\
\hline Consumption of Milk & 57.7 & 53.3 & -4.4 & 0.010 \\
\hline Healthy Breakfast & 86.0 & 91.0 & 5.0 & 0.010 \\
\hline Outdoor Activity & 66.0 & 78.6 & 12.6 & 0.001 \\
\hline Healthy Snacks & 75.0 & 83.5 & 8.5 & 0.001 \\
\hline Healthy Clean Living Behavior (PHBS) & 62.5 & 68.5 & 6.0 & 0.001 \\
\hline
\end{tabular}

* The score is standardized with the minimum value 0 and the maximum value 100

In 2015 (Table 4), most variables increased the level of knowledge before and after the Gernus intervention. But on the PGS variable - Side Dishes Group (0.145), Milk Consumption (0.094), Outdoor Physical Activity (0.835), and PHBS (0.226) have increased before and after Gernus intervention. The p-value is more than 0.05 , which means that it is statistically not significant.

Changes in the value of the PHBS variable did not increase (-1.5) before and after Gernus intervention. The lowest level of knowledge before the intervention is PGS (27.0), and PGSWater Consumption (0.27), and the highest value is on the Healthy Snack variable (85.0). The lowest knowledge after the intervention is on the PGS variable (56.5), and the highest is Healthy Snacks (90.3). Meanwhile, for the change in the value of knowledge (d) the smallest is the PHBS variable (-1.5), and the largest is the variable Water Intake (41.0). The KAP study in 2015, there were no questions about healthy breakfast, but training materials on healthy breakfast were still provided following the previous year.

Table 4. Change of Knowledge Before and After Gernus Nutrition Education Intervention in 2015

\begin{tabular}{|c|c|c|c|c|}
\hline \multirow{3}{*}{ Student Nutrition Education Materials } & \multicolumn{4}{|c|}{2015} \\
\hline & \multicolumn{3}{|c|}{ Score* } & \multirow{2}{*}{ p-value } \\
\hline & before & after & $\mathbf{d}$ & \\
\hline Types of Nutrients and Their Functions & 52.0 & 73.7 & 21.7 & 0.001 \\
\hline Guidelines for Balanced Nutrition (PGS) & 27.0 & 56.5 & 29.5 & 0.001 \\
\hline PGS - Tumpeng and your Dishes & 56.8 & 67.7 & 10.9 & 0.001 \\
\hline PGS - Staple Food Group & 54.7 & 61.0 & 6.3 & 0.001 \\
\hline PGS - Fruit \& Vegetables Group & 46.3 & 63.0 & 16.7 & 0.001 \\
\hline PGS - Fruit \& Vegetables Colours Group & 70.0 & 79.0 & 9.0 & 0.001 \\
\hline PGS - Compelemtary food & 55.5 & 58.0 & 2.5 & 0.145 \\
\hline PGS - Water Consumption & 27.0 & 68.0 & 41.0 & 0.001 \\
\hline Consumption of Milk & 79.0 & 81.0 & 2.0 & 0.094 \\
\hline Outdoor Activity & 72.0 & 72.3 & 0.3 & 0.835 \\
\hline Healthy Snacks & 85.0 & 90.3 & 5.3 & 0.001 \\
\hline Healthy Clean Living Behavior (PHBS) & 66.5 & 65.0 & -1.5 & 0.226 \\
\hline
\end{tabular}

*The score is standardized with the minimum value 0 and the maximum value 100 
The difference in knowledge in 2016 (Table 5) as a whole increased between before and after Gernus intervention. T-test results show all variables that have a p-value of less than 0.05 $(p=0.001)$ were statistically significant. There are differences in the level of knowledge before and after the intervention. The lowest knowledge value before the intervention is PGS (27.5). The lowest value is PGS-Fruits and Vegetables Group (69.3). The highest value before and after is the Healthy Snack variable (85.0 and 89.5). Meanwhile, for the change in the value of knowledge (d), the smallest in the Healthy Snack variable (4.5) and the largest is in the Balanced Nutrition Guidelines variable (PGS) (42.5).

Table 5. Change of Knowledge Before and After Gernus Nutrition Education Intervention in 2016

\begin{tabular}{|c|c|c|c|c|}
\hline \multirow{3}{*}{ Student Nutrition Education Materials } & \multicolumn{4}{|c|}{2016} \\
\hline & \multicolumn{3}{|c|}{ Score* } & \multirow{2}{*}{ p-value } \\
\hline & before & after & $\mathbf{d}$ & \\
\hline Types of Nutrients and Their Functions & 57.0 & 71.1 & 14.1 & 0.001 \\
\hline Guidelines for balanced nutrition (PGS) & 27.5 & 70.0 & 42.5 & 0.001 \\
\hline PGS - Tumpeng and Your Dishes & 56.0 & 71.6 & 15.6 & 0.001 \\
\hline PGS - Staple Food Group & 61.7 & 73.7 & 12.0 & 0.001 \\
\hline PGS - Fruit \& Vegetables Group & 53.7 & 69.3 & 15.6 & 0.001 \\
\hline PGS - Fruit \& Vegetables Colours Group & 74.0 & 87.0 & 13.0 & 0.001 \\
\hline PGS - Complemenraty food & 62.5 & 69.5 & 7.0 & 0.001 \\
\hline PGS - Water Consumption & 34.0 & 76.0 & 42.0 & 0.001 \\
\hline Consumption of Milk & 78.5 & 83.5 & 5.0 & 0.001 \\
\hline Healthy Breakfast & 74.5 & 83.5 & 9.0 & 0.001 \\
\hline Outdoor Activity & 69.3 & 77.0 & 7.7 & 0.001 \\
\hline Healthy Snacks & 85.0 & 89.5 & 4.5 & 0.001 \\
\hline Healthy Clean Living Behavior (PHBS) & 34.0 & 76.0 & 42.0 & 0.001 \\
\hline
\end{tabular}

*The score is standardized with the minimum value 0 and the maximum value 100

Based on Table 6 in the 2017 PGS - Side Dishes Group (0.051) and Milk Consumption (0.163), there was an increase in knowledge value. The statistically has a p-value $>0.05$, meaning there is no significant difference between before and after the intervention. The lowest level of knowledge before the intervention is the PGS variable, PGS-Water Consumption, and PHBS (43.0). The lowest value after the intervention is the PGS-Fruit and Vegetables Group (59.7). The highest value before and after the intervention is the Healthy Snack variable (89.5 and 92.0). The highest change in the value of knowledge (d) is in the variable PGS-Water Intake (36.0) and Healthy Clean Living Behavior (PHBS) (36.0).

Table 6. Change of Knowledge Before and After Gernus Nutrition Education Intervention in 2017

\begin{tabular}{|c|c|c|c|c|}
\hline \multirow{3}{*}{ Student Nutrition Education Materials } & \multicolumn{4}{|c|}{2017} \\
\hline & \multicolumn{3}{|c|}{ Score* } & \multirow{2}{*}{ p-value } \\
\hline & before & after & d & \\
\hline Types of Nutrients and Their Functions & 52.4 & 64.0 & 11.6 & 0.001 \\
\hline Guidelines for balanced nutrition (PGS) & 43.0 & 73.5 & 30.5 & 0.001 \\
\hline PGS - Tumpeng and Your Dishes & 51.6 & 61.4 & 9.8 & 0.001 \\
\hline PGS - Staple Food Group & 52.0 & 66.0 & 14.0 & 0.001 \\
\hline PGS - Fruit \& Vegetables Group & 49.0 & 59.7 & 10.7 & 0.001 \\
\hline PGS - Fruit \& Vegetables Colours Group & 69.0 & 80.0 & 11.0 & 0.001 \\
\hline PGS - Complementary food & 57.5 & 62.5 & 5.0 & 0.051 \\
\hline PGS - Water Consumption & 43.0 & 79.0 & 36.0 & 0.001 \\
\hline
\end{tabular}




\begin{tabular}{lrrrr}
\hline Consumption of Milk & 81.5 & 84.0 & 2.5 & 0.163 \\
Healthy Breakfast & 77.0 & 86.0 & 9.0 & 0.001 \\
Outdoor Activity & 73.3 & 80.7 & 7.4 & 0.001 \\
Healthy Snacks & 89.5 & 92.0 & 2.5 & 0.043 \\
Healthy Clean Living Behavior (PHBS) & 43.0 & 79.0 & 36.0 & 0.001 \\
\hline
\end{tabular}

* The score is standardized with the minimum value 0 and the maximum value 100

In 2018 (Table 7), the value of the difference in knowledge increased, and the t-test results obtained a p-value less than 0.05 , which statistically significant. There were significant differences before and after the intervention. However, in the PGS variable - the Vegetable and Fruit Color Group (0.081) and the Physical Activity variable (0.551) p-value $>0.05$, there were no statistically significant differences before and after the intervention.

The Milk Consumption Variable did not increase in value (-1.0), but the p-value 0.77 was statistically no significant difference before and after the Gernus intervention. The highest value before $=$ the intervention is variable Milk Consumption (79.0), while for the lowest postintervention value is the variable PGS-Water Intake (34.0) and PHBS (34.0). The biggest change in the value of knowledge (d) in 2018 was on the variable PGS-Water Intake (45.0) and PHBS (45.0), while for the smallest change in value (d) is the Milk Consumption variable (-1.0). In 2018 questions about Healthy Breakfast and Healthy Snacks were not available, but training materials were still provided as in previous years.

Table 7. Change of Knowledge Before and After Gernus Nutrition Education Intervention in 2018

\begin{tabular}{|c|c|c|c|c|}
\hline \multirow{3}{*}{ Student Nutrition Education Materials } & \multicolumn{4}{|c|}{2018} \\
\hline & \multicolumn{3}{|c|}{ Score* } & \multirow{2}{*}{ p-value } \\
\hline & before & after & $\mathbf{d}$ & \\
\hline Types of Nutrients and Their Functions & 42.8 & 63.1 & 20.3 & 0.001 \\
\hline Guidelines for balanced nutrition (PGS) & 21.6 & 44.3 & 22.7 & 0.001 \\
\hline PGS - Tumpeng and Your Dishes & 52.6 & 69.8 & 17.2 & 0.001 \\
\hline PGS - Staple Food Group & 41.3 & 65.7 & 24.4 & 0.001 \\
\hline PGS - Fruit \& Vegetables Group & 57.3 & 68.0 & 10.7 & 0.001 \\
\hline PGS - Fruit \& Vegetables Colours Group & 68.0 & 75.0 & 7.0 & 0.081 \\
\hline PGS - Complementary food & 50.0 & 72.0 & 22.0 & 0.001 \\
\hline PGS - Water Consumption & 34.0 & 79.0 & 45.0 & 0.001 \\
\hline Consumption of Milk & 79.0 & 78.0 & -1.0 & 0.770 \\
\hline Outdoor Activity & 71.0 & 72.3 & 1.3 & 0.551 \\
\hline Healthy Clean Living Behavior (PHBS) & 34.0 & 79.0 & 45.0 & 0.001 \\
\hline
\end{tabular}

* The score is standardized with the minimum value 0 and the maximum value 100

\section{Discussion}

Nutrition education content in the school intracuricular curriculum, The Curriculum 2013, is not studied on every subject theme and is not available at every grade level. Nutrition education content is only studied in class I, class III, class IV and class V. Nutrition content in Curriculum 2013 textbook includes the Balanced Nutrition Guidelines (PGS) in the book Balanced Nutrition Message for School Children (Pesan Gizi Seimbang Anak Sekolah/PJAS) by BPOM RI namely (1) eating a variety of foods, (2) getting used to clean living behavior, (3) physical activity, (4) maintaining and monitoring normal weight (BB) [16] [17]. 
In Table 1. it appears that relating to the first PGS, eating a variety of foods, is discussed in class IV textbooks with sub-themes "the benefits of healthy and nutritious food for growth" with a total score of 5 (five), meaning that the material is described in full and presented in sentences and pictures.

For the second PGS, getting used to clean living, is studied at grade I level on how to maintain the cleanliness of the body and clothing with a total of 5 (five) points, how to take care of the body, actions taken at home in maintaining environmental cleanliness with point 4 (four), and Practice on how to take care of the body (how to brush teeth, how to wash hands, how to shower and wash) with a total score of 2 (two).

The third PGS, carrying out physical activities, is studied at each grade level, but the importance of physical activity is explained at grade I with the sub-theme of sports benefits with a total score of 4 (four), the material is shortly described but presented with pictures and sentences. In grade 5 textbooks, related to the fourth PGS, maintaining and monitoring a normal $\mathrm{BB}$ has been explained that monitoring weight is important, and explained the difference between children who are underweight, normal and overweight in the sub-theme of the table on nutritional needs adjusted for body weight, height, age with a total score of 4 points (four) and identify children who are malnourished, obese children with a total score of 2 (two) because they are shortly explained and presented with pictures.

Breakfast is also a priority in the nutrition intake of school children. Breakfast in the morning provides many benefits for children, including the entrance of nutrients that will be used for activities during the day, increase the concentration of learning, reduce the possibility of unhealthy snacks, reduce snacking habits that will be at risk of obesity [16] [17]. In Curriculum 2013 textbooks, an explanation of breakfast and healthy snacks was found. The material is described in a complete paragraph about the benefits of breakfast, and presented in sentences. The material about breakfast is studied at grade IV level on the sub theme "habits of eating healthy and nutritious food in the morning" with a total point of 5 (five). Explanation of healthy snacks is briefly explained and presented with pictures and sentences at grade III level, on the sub theme "Healthy Snacks" with a total score of 4 (four).

So overall the nutritional content in the intracuricular curriculum is good, but still not optimal. The highest score obtained is 5 (five) points from the maximum total score of 6 (six) points. In other words, the nutrition content in the current curriculum needs to be developed and modified in a better direction, involving various stakeholders, families and communities, such as WHO's recommendations through the program Nutrition Friendly School Initiative (NFSI) in 2006 which is school-based nutrition education, includes five components, namely the school's written policy on nutrition (also called the Nutrition Friendly School Policy), increasing the awareness and capacity of the school community, curriculum development and modification, creating a supportive school environment for optimal nutrition and health, and school nutrition and health services [18].

Based on Table 2. the nutrition content in the flipchart and gernus student nutrition education books shows that according to the type of description and presentation, the highest score can be achieved. The nutritional content in flipchart and nutritional education books is shortly and completely described in line with the nutrition content in the Curriculum 2013 textbooks. The nutritional content described by Gernus complements and adds material to the Curriculum 2013, most of which are shortly described. The addition of material by Gernus specifically about the color group of fruits and vegetables and the concept of healthy snacks and the benefits of consuming milk.

Gernus as an extracurricular activity will support subject matter in the intracuricular curriculum because this extracurricular activity involves health promotion to parents of students, 
which is one of the programs that makes gernus different from nutrition education programs to improve nutrition knowledge. This is in line with research conducted by Zulaekha regarding comprehensive nutrition education to prevent anemia that comprehensive nutrition education involving children, parents/guardians and teachers combined with the provision of direct intake to children is more effective and has a positive impact compared to if only given education only [7].

From KAP study conducted by Gernus and PKGK UI, it can be seen that there are positive changes in students' nutritional knowledge before and after the intervention is given. The provision of nutrition education to students, including the social environment of students, is proven to be able to improve students' knowledge, attitudes, and nutritional behavior. According to DeCosta et al., children's behavior is influenced by peers, teachers, adults, and parents [19].

Parents play an important role in child eating practice a such as controlling children, feeding, involving children in the selection and provision of food, and providing food education to their children. Parents who provide optimal eating practices have 8 times the chance to have children with normal nutritional status compared to parents who are less than optimal in feeding [20]. In addition, parents' attitudes towards healthy eating also affect children's nutritional knowledge indirectly through parental nutrition knowledge. This shows that increasing parents' nutritional knowledge helps improve children's knowledge regardless of the socioeconomic status of parents [21].

A study in France, children aged 9-11 reported that parents were the main source of their nutritional information, followed by school teachers, television, and doctors. Parents with good nutrition knowledge are more likely to have children with good nutrition knowledge [21]. In addition, parental partnerships with schools affect children's knowledge, attitudes, and skills. Studies conducted at 30 elementary schools in Metro City, Lampung show that parental involvement through school committees can influence the competency of students' knowledge, attitudes, and skills as a result of effective school programs [22]. So, training is needed to improve parents' nutritional knowledge.

Training of teachers through counseling or other forms of refreshment is very necessary for school teachers and students to update their existing knowledge. Teachers are an important source of information for students. If the teacher has the right knowledge, it is hoped that this information will be conveyed well to the students [23]. Teacher training using videos, PPT, and flipcharts with interesting animations also plays a role in increasing the nutrition knowledge of teachers and students.

According to Hamida in Solehati et al., the counseling method, which is conducted in both directions and uses attractive images, is important in conveying information. The media used in the learning process will cause the learning process to be more interesting so that it can be easily understood and causes the target not to become bored quickly. Teachers and students become not bored and easily understand what material is delivered [23]. In line with research by Wuryanti and Badru, teachers also need professional development in the application of pedagogical skills to improve teaching and learning. Teachers are expected to be more skilled and provide facilities to support learning. That is, that among various learning media video technology is believed to be very useful and suitable for problem-based learning because it can convey settings, characters, and actions in interesting ways and can describe complex and interconnected problems [24].

Peer training conducted by Gernus also plays a role in increasing children's nutritional knowledge. According to DeCosta et al., children are more likely to imitate their peers' eating behavior because they think that eating behavior is a common thing that is accepted and liked by their age group [19]. Peer groups allow individuals to interact with each other, get along, and 
give spirit and motivation to other peers emotionally. Emotional ties in the life of the peer group will bring a variety of benefits and a great influence on individuals who are in the group [25].

\section{Conclusion}

Gerakan Nusantara, as extracurricular activities in schools together with nutrition education through intracuricular curriculum, can improve the nutrition knowledge of elementary school children. The success of the Gerakan Nusantara was achieved because the program of activities involved all groups related to the social environment of students, namely teachers at school, peers, and parents, activities were carried out significantly through student training, practice, and provision of healthy food. Gernus as an extracurricular activity along with lessons in the intracuricular curriculum that are learned in schools. This extracurricular activity is needed to support the limitations of nutrition education in the intracuricular curriculum. Extracurricular activities to improve the nutrition knowledge of elementary school children should need attention from various parties. The sustainability of Gernus as an extracurricular activity must be maintained and monitored so that the results of this nutrition education can be applied and enjoyed by all Indonesian children.

\section{References}

[1] Indonesian Ministry Of Health, "Info DATIN Pusat Informasi dan Informasi Kementrian Kesehatan RI STATUS GIZI 2016,” Jakarta, 2016.

[2] Indonesian Ministry of Education and Culture, "Media Komunikasi dan Inspirasi JENDELA Pendidikan dan Kebudayaan Edisi XVI/Oktober," 2017.

[3] FAO, "Nutrition Education in Primary Schools Vol. 1: The Reader. Food and Agriculture Organization," 2005.

[4] L. Drake, R. Russo, and M. (Greta) A. Defeyter, "Editorial: The Impact of School Food Consumption on Children's Cognition, Educational Attainment and Social Development," Front. Public Heal., vol. 5, Aug. 2017.

[5] D. R. Fadhilah, "Urgensi Gizi dan Kesehatan Peserta Didik Tingkat SD/MI Sebagai Prasyarat Terwujudnya Generasi Emas,” Univ. Islam Negeri Syarif Hidayatullah Jakarta, 2015.

[6] Priyali Shah; Anoop Misra; et al, "Improvement in nutrition-related knowledge and behaviour of urban Asian Indian school children: Findings from the Medical education for children/Adolescents for Realistic prevention of obesity and diabetes and for healthy aGeing (MARG) intervention study," Br. J. Nutr., vol. 3, no. 104, pp. 427-436, 2010.

[7] S. Zulaekah, "PERAN PENDIDIKAN GIZI KOMPREHENSIF UNTUK MENGATASI MASALAH ANEMIA DI INDONESIA," J. Kesehat., vol. 2, pp. 169-178, 2009.

[8] WHO, "Food and nutrition policy for schools A tool for the development of school nutrition programmes in the European Region," 2006.

[9] J. Sherman and E. Muehlhoff, "Developing a Nutrition and Health Education Program for Primary Schools in Zambia," J. Nutr. Educ. Behav., 2007.

[10] R. Adhistiana, A. Khomsan, and L. Amalia, "IDENTIFIKASI MUATAN GIZI DALAM MATA PELAJARAN DI SEKOLAH DASAR BANTARJATI 5 BOGOR," J. Gizi dan Pangan, vol. 4, no. 3, p. 151, Nov. 2009.

[11] H. F. Delisle, O. Receveur, V. Agueh, and C. Nishida, "Pilot project of the Nutrition-Friendly School Initiative (NFSI) in Ouagadougou, Burkina Faso and Cotonou, Benin, in West Africa," Glob. Health Promot., vol. 20, no. 1, pp. 39-49, 2013.

[12] Indonesian Ministry of Education and Culture, "Permendikbud No 62 tahun 2014," 2014. 
[13] W. Nartoatmojo, "Ektrakurikuler di Sekolah : Dasar Kebijakan dan Aktualisasinya," 2010.

[14] Frisian Flag Indonesia, "Gerakan Nusantara.".

[15] Indonesian Ministry of Education and Culture, "Model Silabus Sekolah Dasar/Madrasah Ibtidayah Tematik Terpadu," 2017.

[16] Indonesia National Agency of Drug and Food Control, "Pedoman Pangan Jajanan Anak Sekolah Untuk Pencapaian Gizi Seimbang," Jakarta, 2013.

[17] Indonesian Ministry Of Health, "Pedoman Gizi Seimbang," 2014.

[18] WHO, "WHO | Nutrition-friendly schools initiative (NFSI)," WHO, 2014.

[19] P. DeCosta, P. Møller, M. B. Frøst, and A. Olsen, "Changing children's eating behaviour - A review of experimental research.," Appetite, vol. 113, pp. 327-357, 2017.

[20] Z. P. Perdani, R. Hasan, and N. Nurhasanah, "HUBUNGAN PRAKTIK PEMBERIAN MAKAN DENGAN STATUS GIZI ANAK USIA 3-5 TAHUN DI POS GIZI DESA TEGAL KUNIR LOR MAUK," J. JKFT, vol. 2, no. 2, p. 9, Mar. 2017.

[21] D. Zarnowiecki, N. Sinn, J. Petkov, and J. Dollman, "Parental nutrition knowledge and attitudes as predictors of 5-6-year-old children's healthy food knowledge," Public Health Nutr., no. 7, pp. $1284-1290$.

[22] B. Rahman FKIP Universitas Lampung and J. Soemantri Brojonegoro No, "KEMITRAAN ORANG TUA DENGAN SEKOLAH DAN PENGARUHNYA TERHADAP HASIL BELAJAR SISWA."

[23] T. Solehati, S. Susilawati, M. Lukman, and C. E. Kosasih, "PENGARUH EDUKASI TERHADAP PENGETAHUAN DAN SKILL GURU SERTA PERSONAL HYGIENE SISWA SD,” J. Kesehat. Masy., vol. 11, no. 1, p. 135, Sep. 2015.

[24] U. Wuryanti and B. Kartowagiran, "PENGEMBANGAN MEDIA VIDEO ANIMASI UNTUK MENINGKATKAN MOTIVASI BELAJAR DAN KARAKTER KERJA KERAS SISWA SEKOLAH DASAR," J. Pendidik. Karakter, vol. 6, no. 2, Dec. 2016.

[25] A. T. Afandi, R. Indarwati, and S. Hadisuyatmana, "PENGARUH PEER GROUP SUPPORT TERHADAP PERILAKU JAJANAN SEHAT SISWA KELAS 5 SDN AJUNG 2 KALISAT JEMBER,” Indones. J. Community Heal. Nurs., vol. 1, no. 1, Feb. 2019. 